\title{
A!
}

This is an electronic reprint of the original article.

This reprint may differ from the original in pagination and typographic detail.

Sundaria, R.; Nair, D. G.; Lehikoinen, A.; Arkkio, A.; Belahcen, A.

\section{Loss Model for the Effects of Steel Cutting in Electrical Machines}

Published in:

Proceedings of the 2018 23rd International Conference on Electrical Machines, ICEM 2018

DOI:

10.1109/ICELMACH.2018.8506822

Published: 24/10/2018

Document Version

Peer reviewed version

Please cite the original version:

Sundaria, R., Nair, D. G., Lehikoinen, A., Arkkio, A., \& Belahcen, A. (2018). Loss Model for the Effects of Steel Cutting in Electrical Machines. In Proceedings of the 2018 23rd International Conference on Electrical Machines, ICEM 2018 (pp. 1260-1266). [8506822] IEEE. https://doi.org/10.1109/ICELMACH.2018.8506822

This material is protected by copyright and other intellectual property rights, and duplication or sale of all or part of any of the repository collections is not permitted, except that material may be duplicated by you for your research use or educational purposes in electronic or print form. You must obtain permission for any other use. Electronic or print copies may not be offered, whether for sale or otherwise to anyone who is not an authorised user. 


\title{
Loss Model for The Effects of Steel Cutting in Electrical Machines
}

\author{
R. Sundaria, D. G. Nair, A. Lehikoinen, A. Arkkio and A. Belahcen, Senior member, IEEE
}

\begin{abstract}
Epstein frame measurements of electrical steel samples of different widths cut by laser cutting are carried out in the range of $20 \mathrm{~Hz}$ to $400 \mathrm{~Hz}$ frequency of sinusoidal excitations. The effect of cutting on the magnetic permeability with core losses are modeled with analytical equations. Further, the validation of the model is carried out with finite element simulations of electrical steel samples. The presented loss model is found to reproduce the measurement results reasonably. The loss model is then applied to the simulation of a cage induction machine with time-stepping finite element analysis. The electromagnetic and thermal performance of the machine was analyzed with respect to the cutting effect. The simulations shows increase in the computed core losses and temperatures due to the cutting effect.
\end{abstract}

Index Terms-Core loss, cutting, cut edge, electrical machines, finite element modeling, steel cutting, steel laminations.

\section{INTRODUCTION}

Manufacturing of electrical machines in general involves cutting of electrical steel sheets to appropriate sizes, welding of steel stacks and shrink fitting. Each of these manufacturing steps seems to have an impact on losses in the final manufactured machine. Among these losses, the losses due to cutting seem to garner the interest of the research community in the last couple of decades. Electrical sheets are typically cut by punching or laser cutting, which have a significant impact on the magnetic properties of iron. Researchers have performed the magnetic measurements with the help of standard Epstein frame and single sheet tester. The generated plastic, residual and thermal stresses seem to translate into a drop in permeability and increase in core loss density [1][3]. Various authors proposed loss models dependent on the distance from the cut-edge to include the effect of cutting on the magnetic permeability and core-losses. Some have suggested to include a region of uniformly degraded material [4], [5] whereas others preferred a continuous function of cut-edge distance for representing the magnetic degradation [6], [7]. The difficulty in reproducing the measurement results from a proposed loss model is observed due to a nonlinear relationship of cut-edge distance with the permeability and core-loss density. Further, an additional difficulty in analyzing the cutting effect with finite element analysis (FEA) is posed

This research work has received funding from the European Research Council under the European Unions Seventh Framework Programme (FP7/2007-2013) / ERC Grant Agreement n. 339380.

R. sundaria, D. G. Nair, A. Lehikoinen, A. Arkkio and A. Belahcen are with Department of Electrical Engineering and Automation, Aalto University, Espoo, 15500, Finland (e-mail: ravi.sundaria@aalto.fi). by the heavy computational time requirements. Recently the application of higher order elements for efficient computation of cutting effect was studied [8].

In this paper, authors propose a loss model which is inspired by [6], [7] and resonably reproduce the measurement results. In contrast to the literature [6], [7], the effect of cutting is included into three component core loss formula [9], namely hysteresis loss, eddy current loss and excess loss components. Further possible difficulties in non-linear newton raphson iterations were highlighted. The proposed loss model is then verified by the FEA of simplified Epstein frame measurement model. Moreover, the computationally efficient time-harmonic higher order approach described in [8] to model cutting effect is extended to higher order timestepping method in this paper. At the end, the effect of cutting on the thermal and electromagnetic performance of the machine was analyzed.

\section{METHOD}

This section is divided into three subsections: first subsection deals with the magnetic measurements of laser cut samples of different widths with the standard Epstein frame. The second section describes the proposed loss model and a time-stepping finite element model with higher order elements is presented in the last subsection to efficiently model the cutting effect.

\section{A. Epstein Frame Measurements}

Magnetic measurements are performed usually on electrical steel samples with Epstein frame or single sheet testers in the industry as well as academia. As presented in the literature, many researchers have studied the effect of cutting by studying electrical steel samples of different widths. Following the same lines, this paper presents results of five different types of samples having the same total material mass. The assembly of different width samples are also shown in Fig. 1. The details of the measured samples are presented in Table I.

The magnetic measurements are performed with standard Epstein frame setup "MPG 100 D" by Brockhaus Measurements following the standard IEC: 604004-2. The measured magnetic flux density was controlled to be sinusoidal. The electrical steel samples were demagnetized before the measurements and air flux compensation was considered with the help of the mutual inductor in the test setup. Five different sinusoidal excitation frequencies were considered, as $20 \mathrm{~Hz}$, $50 \mathrm{~Hz}, 100 \mathrm{~Hz}, 200 \mathrm{~Hz}$ and $400 \mathrm{~Hz}$. As a result single valued 

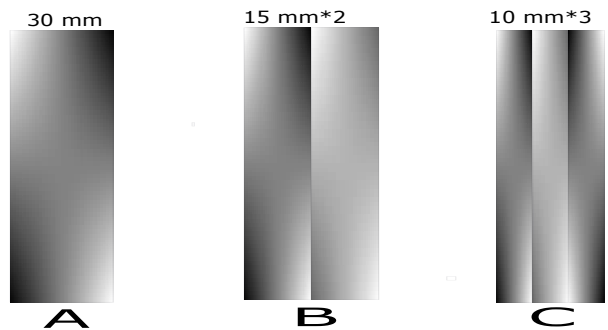

Fig. 1. Assembly of different width samples for magnetic measurements. Sample D and E are assembled in similar manner.

TABLE I

TEST SAMPLES

\begin{tabular}{|c|c|c|}
\hline Sample & Detail & $\begin{array}{c}\text { Total width } \\
(\mathbf{m m})\end{array}$ \\
\hline A & Standard Epstein frame sample of 30 mm & $1 \times 30=30$ \\
\hline B & Two 15 mm samples joined together & $2 \times 15=30$ \\
\hline C & Three 10 mm samples joined together & $3 \times 10=30$ \\
\hline D & Six 5 mm samples joined together & $6 \times 5=30$ \\
\hline E & Ten 3 mm samples joined together & $10 \times 3=30$ \\
\hline
\end{tabular}

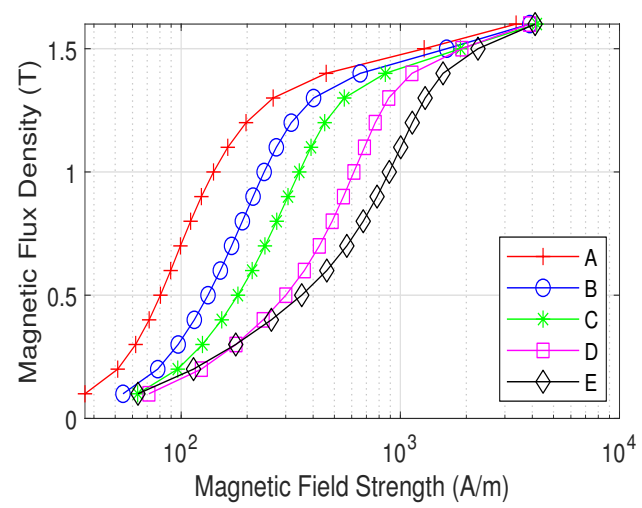

Fig. 2. Measured magnetization curves at $50 \mathrm{~Hz}$ for different width samples

magnetization curve in form of a peak value of magnetic flux density $\left(B_{p}\right)$ and peak value of magnetic field strength $\left(H_{p}\right)$ along with specific core loss density curve in form of loss density $P_{c}$ versus $B_{p}$ were obtained. The effect of cutting on magnetic permeability can be analyzed from Fig. 2 which is showing $\mathrm{BH}$ curve at $50 \mathrm{~Hz}$ of different samples. Further, the core loss increase due the cutting is presented in terms of core loss density in Figs. $3 \mathrm{a}$ and 3b, measured at excitation frequencies $50 \mathrm{~Hz}$ and $400 \mathrm{~Hz}$ respectively.

\section{B. Loss model}

We can observe the increase in core losses and decrease in permeability due to the cutting effect in the above presented magnetic measurements. Therefore, in the following an analytical expression is presented to account for the cutting effect.

1) Effect on permeability: From measurements, it is quite evident that the effect of cutting on the magnetic permeability is mainly dependent of two parameters: namely the magnetic

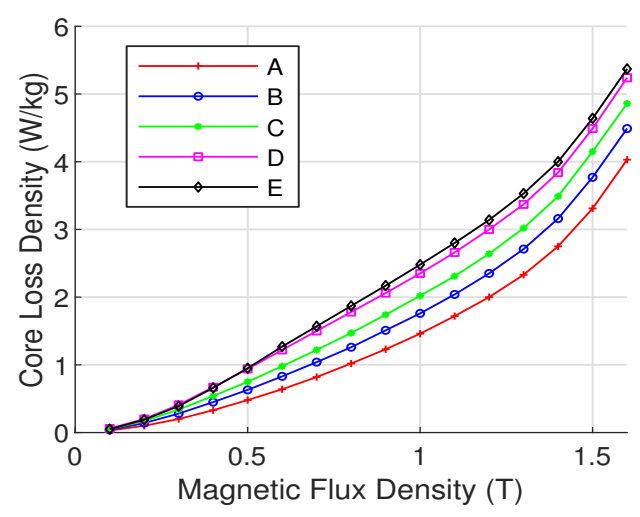

(a)

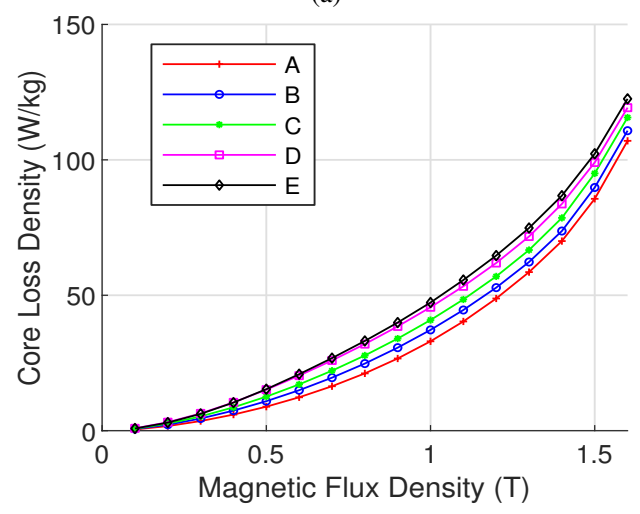

(b)

Fig. 3. Measured core loss curves of different width samples at (a) $50 \mathrm{~Hz}$ (b) $400 \mathrm{~Hz}$.

field strength $(H)$ and distance from cut-edge $(x)$. Further, magnetic field strength $(H)$ is assumed constant across the measured sample. The local magnetic permeability $\mu(H, x)$ is presented in (1). Here $\Delta \mu(H)$ and $a$ are fitting parameters, therefore, $n$ number of data points will result in $n+1$ fitting parameters. This loss model is inspired by [6] and [7]. $\mu_{n}(H)$ is magnetic permeability of non-degraded material. It should be noted that we will obtain the average measured permeability $\left(\tilde{\mu_{m}}\right)$ from magnetic measurements and corresponding average calculated permeability $\left(\tilde{\mu_{c}}\right)$ can be determined from (2) for a sample of lamination width $w$.

$$
\begin{aligned}
& \mu(H, x)=\mu_{\mathrm{n}}(H)-\Delta \mu(H) e^{-a x} \\
& \tilde{\mu}_{c}(H, w)=\frac{2}{w} \int_{0}^{w / 2} \mu(H, x) d x
\end{aligned}
$$

2) Effect on core losses: Similar to the permeability of the measured material it is also quite clear that core losses are affected due to cutting. One important aspect of losses to be analyzed is that which loss component among hysteresis, eddy current and excess loss is impacted largely due to the cutting. Due to the physical nature of the cutting effects and also as discussed in literature [6], [7], the hysteresis loss was considered to be affected by the cutting.

This paper will modify the hysteresis loss coefficient of the three component core loss formula presented in [9]. The three component core loss formula (3) have coefficients of 
eddy current $K_{e}$, excess loss $K_{e x}$ and exponent $\alpha$ which are cubic polynomials of $B$. This paper fixed the parameters such as $K_{h 0}, \alpha, K_{e}$, and $K_{e x}$ at non-degraded value. Flux density dependent eddy current and excess loss coefficients was selected to improve the overall fitting of the cut-edge loss model. The effect of cutting is then included in the hysteresis loss coefficient $K_{h}(B, x)$. It can be noted that the degradation profile of core loss in terms of hysteresis loss coefficient $K_{h}(B, x)$ (4) is exponential function of $x$. Similar expression was used for local magnetic permeability $\mu(H, x)$ (1). As we get the average hysteresis loss coefficient $K_{h m}(B, w)$ from measurements, (4) was averaged along $w$ to obtain the corresponding calculated average hysteresis loss coefficient $\tilde{K_{h c}}(B, w)$ in (5).

$$
\begin{aligned}
P(B, x) & =K_{h}(B, x) B^{\alpha(B)} f+K_{e}(B) B^{2} f^{2} \\
& +K_{e x}(B) B^{1.5} f^{1.5} \\
K_{h}(B, x) & =K_{h 0}+\Delta K_{h}(B) e^{-b(B) x} \\
\tilde{K_{h c}}(B, w) & =\frac{2}{w} \int_{0}^{w / 2} K_{h}(B, x) d x
\end{aligned}
$$

The non-degraded permeability $\mu_{n}(H)$ in (1) and hysteresis loss coefficient $K_{h 0}$ can be derived by magnetic measurement of either annealed or cut by water jet cutting or electron discharge cutting (considered to induce relatively less stress effects) of a standard Epstein frame sample of width $30 \mathrm{~mm}$. In this paper, we have used an enlarged sample of $60 \mathrm{~mm}$ width to derive these non-degraded parameters [10]. The presented expression of local hysteresis loss coefficient was based on [7]. However the dependency of fitting parameters $\Delta K_{h}(B)$ and $b(B)$ on $B$ was kept free rather than linear as presented in [7]. The procedure to derive the fitting parameters is summarized in the flowchart.

\section{Time-stepping FEM Simulation}

The time-stepping FEM analysis of a cage induction machine is based on the voltage source model presented in [11]. The effect of end wind inductances and rotor bar resistances are taken into account with the help of circuit equations. Finite element formulation based on well known $A V$ formulation is written in MATLAB environment. The rotation of rotor is modeled by remeshing air-gap elements at each timestep. Furthermore to study the effect of cutting in the finite element simulation, higher order finite element formulation is adapted which proved to be computationally efficient [8]. As presented by the authors earlier in the case of time-harmonic analysis, the effect of cutting is included in stiffness matrix $S$ in this time-stepping simulation. The entries of the stiffness matrix $S_{i j}$ can be represented in terms of the reluctivity $\nu$ and the nodal shape functions $\phi$ in the domain $\Omega$. The effect of cutting in terms of the degradation of permeability from (1) is presented in the form of the cut distance dependent reluctivity $\nu(A, x)$.

$$
S_{i j}(A, x)=\int_{\Omega} \nu(A, x) \nabla \phi_{i} \cdot \nabla \phi_{j} d \Omega
$$

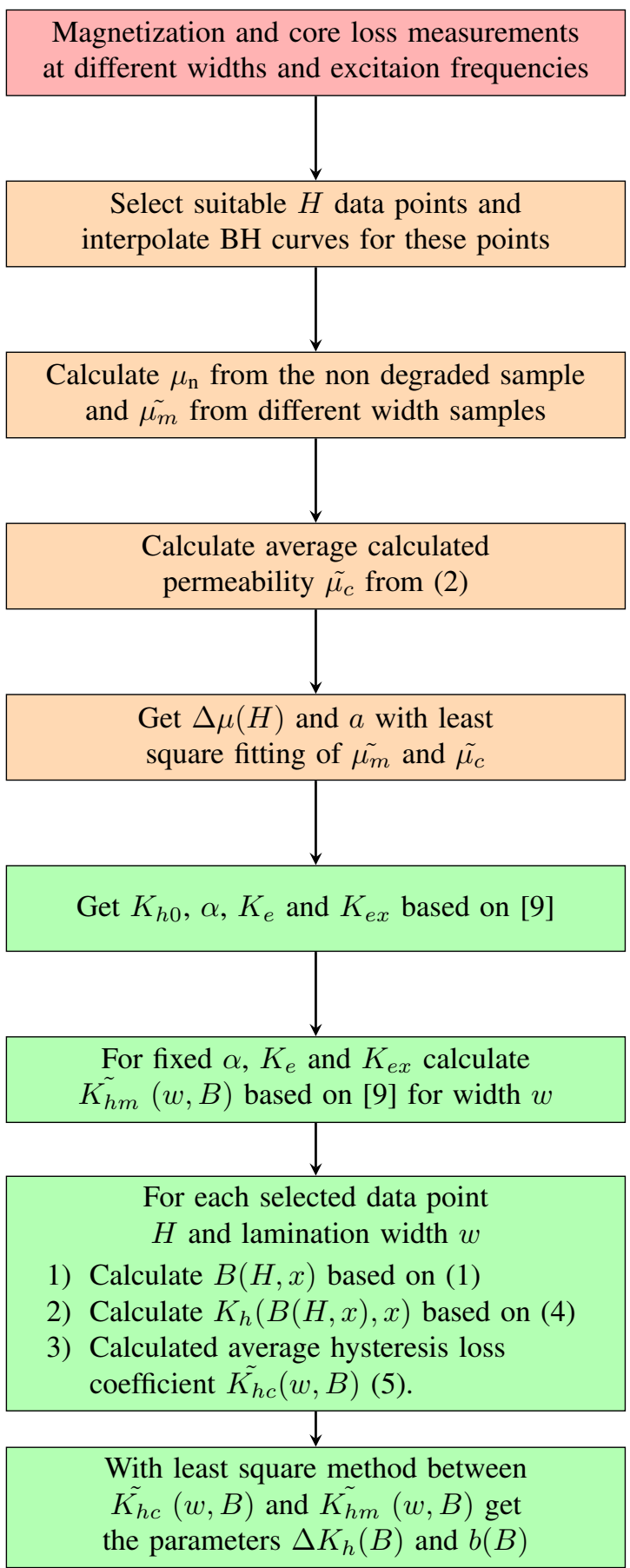

Fig. 4. Flowchart of the loss model

\section{RESULTS}

Under this section, this paper discusses the obtained fitting parameters for the presented loss model and subsequent validation of it. Further, application of the loss model on a cage induction simulated with time-stepping analysis at different load condition is also described. Thermal aspects are analyzed with the help of thermal network model of the machine. 


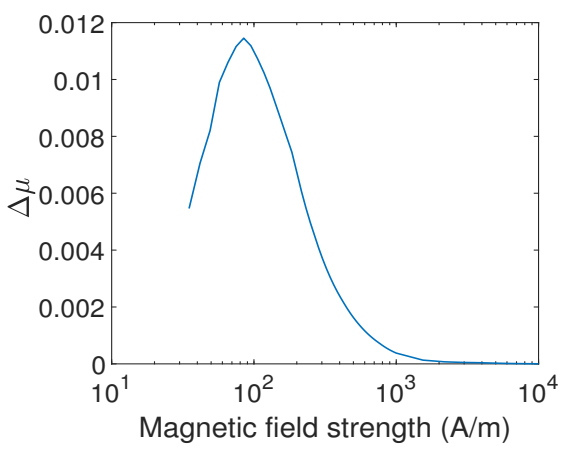

Fig. 5. Fitted parameter $\Delta \mu$. Effect of cutting will be mainly below 1000 $\mathrm{A} / \mathrm{m}$ field strength.

\section{A. Parameter fitting of the loss model}

Under measurements we have obtained the peak value of average magnetic flux density and average core loss density along the width of a sample. Therefore, the proposed local distributions (1) and (3) needs to be averaged in order to compare with the measurements. For fitting, nonlinear least squares toolbox of MATLAB was used.

In case of BH curve fitting, special care needs to be taken for the selection of the data points. Relatively more data points are needed between field strength $30 \mathrm{~A} / \mathrm{m}$ to 1000 $\mathrm{A} / \mathrm{m}$ due more prominent cutting-effect in this range. In this paper about $80 \%$ of the field strength data points are selected uniformly in the range $30 \mathrm{~A} / \mathrm{m}$ to $1000 \mathrm{~A} / \mathrm{m}$ where as remaining $20 \%$ upto $10000 \mathrm{~A} / \mathrm{m}$. The obtained $\Delta \mu$ is presented in the Fig. 5 and the value of $a$ is $267 \mathrm{~m}^{-1}$. The profile of $\Delta \mu$ resembles the drop in average permeability of measured samples which is also listed in the literature. Here for better fitting we can also make parameter $a$ dependent on $H$ [7]; however considerable issues were observed in maintaining the monotonocity of resulting local $\mathrm{BH}$ curves. The nonlinear iteration takes many iterations/doesn't converge if local $\mathrm{BH}$ curves are of non-monotonic nature. Further a non-monotonic curve also doesn't resemble the physical property of electrical steel. By above argument, a constant $a$ was found favourable for the given application.

Similar to the BH curve data, the average hysteresis loss coefficient was obtained and fitted with the corresponding local hysteresis loss coefficient $K_{h}(B, x)$. Further, the fitted average $\tilde{K}_{h}$ is shown in Fig. 6. Here, the measurement data points are between $0.1 \mathrm{~T}$ and $1.5 \mathrm{~T}$. As the loss coefficients are dependent on $B$, loss coefficients out of the measured range are kept constant at the respective limits of $B$.

\section{B. Validation of Proposed Loss Model}

The presented loss model can be verified against the finite element simulation of a simplified Epstein frame measurement system and measurement results. We obtain single value curve in term of peak value of mangnetic flux density and peak value of field strength along with core loss density as $\mathrm{W} / \mathrm{kg}$ from the measurements. Magnetic vector potential based formulation $(A V)$ can be used to solve magnetic field

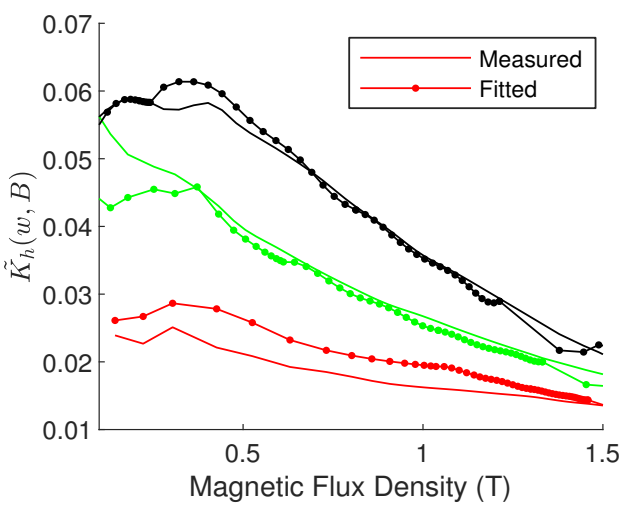

Fig. 6. Fitting results of the average hysteresis loss coefficient $\tilde{K_{m h}}$ $(w, B)$ fitted from measurements and the calculated average hysteresis loss coefficient $\tilde{K_{c h}}(w, B)$. The samples $\mathrm{A}, \mathrm{C}$ and $\mathrm{E}$ are represented by red, green and black colors respectively.

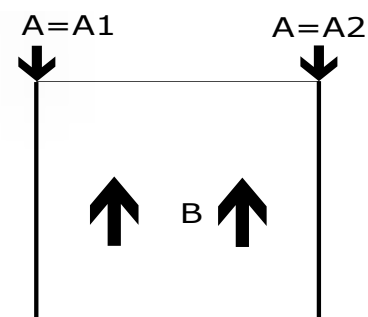

(a)

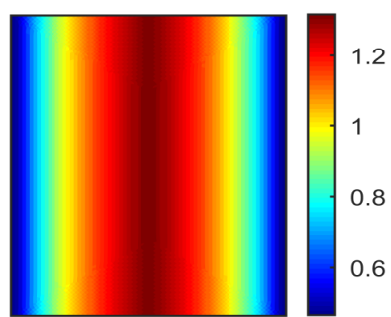

(b)
Fig. 7. (a) Enforcement of average flux density by boundary conditions The bold boundaries represent the Dirichlet boundary conditions whereas other boundaries are imposed with normal Neumann boundary conditions. (b) Magnetic flux density distribution with flux lines when average flux density of $1 \mathrm{~T}$ was enforced.

distribution along the width of the lamination. To avoid the complexities arising from modeling air flux compensation in Epstein frame, this paper will enforce the measured magnetic flux density in rectangular steel sample. Hence, primary and secondary coils are not included FEA simulations. The magnetic flux density can be enforced with the help of a highly dense mesh and Dirichlet boundary condition as presented in the Fig. 7a. The resultant system of equations are presented in (7) and (8). Here $\mathbf{S}, \mathbf{f}$, and $\mathbf{A}$ is stiffness matrix, source vector and magnetic vector potential respectively. As there is no current source in the model, therefore $\mathbf{f}$ can be replaced with zero vector. Finally the simplified equation (8) can be solved for the vector potential $\left(\mathbf{A}_{n}\right)$ at the non Dirichlet nodes of mesh.

$$
\mathbf{S A}=\mathbf{f}
$$

$$
\mathbf{S}_{n, n} \mathbf{A}_{n}+\mathbf{S}_{n, d} \mathbf{A}_{d}=0
$$

The cut-edge dependent local permeability distribution (1) will be applied. This will result in a flux density distribution (Fig 7b) which clearly shows the effect of cutting. As part of post-processing core loss of the sample will be calculated with the help of local core loss curves (3) and (4). Figs 8a and $8 \mathrm{~b}$ represent the calculated and measured core losses at different enforced average magnetic flux densities at different 


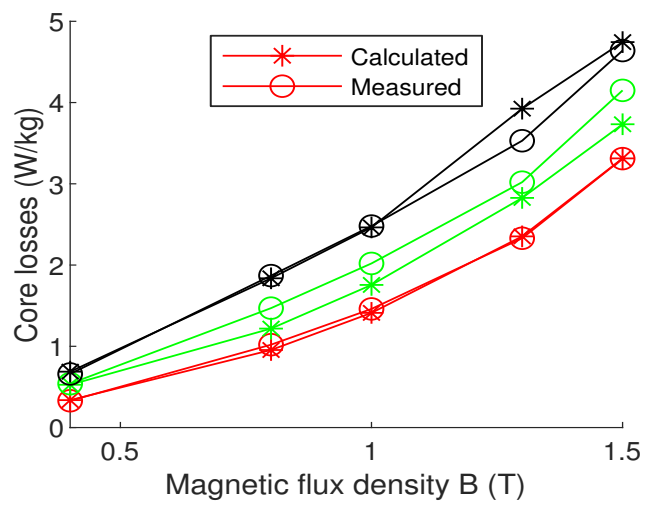

(a)

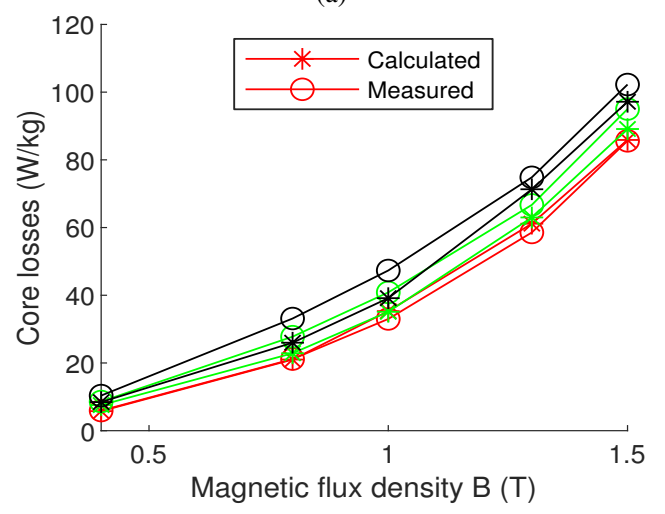

(b)

Fig. 8. Calculated core loss curves of different width samples at (a) 50 $\mathrm{Hz}$ (b) $400 \mathrm{~Hz}$. The samples A, C and E are represented by red, green and black colors respectively.

width of samples at $50 \mathrm{~Hz}$ and $400 \mathrm{~Hz}$ excitation frequencies respectively. The calculated core losses seem to match the measured values reasonably.

\section{Cutting Effect on Machine Performance}

Time-stepping finite element analysis of a cage induction machine was performed. The motor data is presented in the appendix section in Table $\mathrm{V}$. The simulation results were obtained by either considering or not the presented permeability and core-loss models. The effect of cutting is quite easily visible in number of machine parameters. First, as this is voltage source simulation model, the no load current has increased due to lower permeability of iron near the cut-edges as presented in Fig 9a. The core losses computed at no load and full load, both indicate a clear increase in core-loss of full machine as presented in Table II and Table III. The total core-loss has increased about $30 \%$ due to the cutting effect. The distribution of flux density near the cut edges can also be visualized in Fig. 9b, which shows a difference in magnetic flux density distribution with and without the cutting effect. Further analysis has been done on magnetizing current and core-losses at no-load with different supply voltages. Both magnetizing current (Fig. 10a) and core-losses (Fig. 10b) show increase in respective values due to the cutting effect. Additionally, this paper extend the
TABLE II

CUTTING EFFECT ON CORE LOSSES AT NO-LOAD

\begin{tabular}{|c|c|c|c|}
\hline & $\begin{array}{c}\text { No load } \\
\text { without } \\
\text { cutting (W) }\end{array}$ & $\begin{array}{c}\text { No load } \\
\text { with cutting } \\
\text { (W) }\end{array}$ & $\begin{array}{c}\text { \% } \\
\text { Difference }\end{array}$ \\
\hline $\begin{array}{c}\text { Hyst. loss (Stator } \\
\text { yoke) }\end{array}$ & 107.62 & 137.05 & 27 \\
\hline $\begin{array}{c}\text { Hyst. loss (Stator } \\
\text { teeth) }\end{array}$ & 48.45 & 80.14 & 65 \\
\hline Core loss (Stator) & 246.26 & 313.32 & 27 \\
\hline Hyst. loss (Rotor) & 3.58 & 20.15 & 462 \\
\hline Core loss (Rotor) & 49.87 & 64.30 & 29 \\
\hline Total core loss & 296.13 & 377.62 & 27 \\
\hline
\end{tabular}

TABLE III

CUTTING EFFECT ON CORE LOSSES AT FULL-LOAD

\begin{tabular}{|c|c|c|c|}
\hline & $\begin{array}{c}\text { Full load } \\
\text { without } \\
\text { cutting (W) }\end{array}$ & $\begin{array}{c}\text { Full load } \\
\text { with cutting } \\
(\mathbf{W})\end{array}$ & $\begin{array}{c}\text { \% } \\
\text { Difference }\end{array}$ \\
\hline $\begin{array}{c}\text { Hyst. loss (Stator } \\
\text { yoke) }\end{array}$ & 102.01 & 133.09 & 30 \\
\hline $\begin{array}{c}\text { Hyst. loss (Stator } \\
\text { teeth) }\end{array}$ & 53.40 & 104.36 & 95 \\
\hline Core loss (Stator) & 279.62 & 365.79 & 30 \\
\hline Hyst. loss (Rotor) & 6.83 & 35.99 & 426 \\
\hline Core loss (Rotor) & 71.09 & 97.89 & 37 \\
\hline Total core loss & 350.71 & 463.68 & 32 \\
\hline
\end{tabular}

application of computationally efficient time-harmonic based higher order finite element analysis [8] to higher order timestepping analysis with the cutting effect. The computation time is about 40 seconds for solving the resultant system for 200 time-steps.

\section{Thermal Model and Analysis}

A high-fidelity lumped parameter thermal network of the studied totally enclosed fan-cooled (TEFC) motor was formulated for steady-state thermal analysis. It models heat transfer through conduction, convection as well as radiation in the whole machine. The convection coefficients are first determined through generic semi-empirical formulations. The thermal network's accuracy is then improved by adjusting these convection coefficients such that the temperatures it predicted better matched the measured temperatures such as those of the stator winding and motor's frame [12]. The thermal network is presented in the Fig. 11.

As the computed losses indicate that there is clear rise in the core-losses, this paper also analyzes the thermal performance of the studied cage induction machine. To evaluate the thermal implication of the cutting effect on the machine, the input to the thermal network was modified, and the higher core loss resulting from cutting effect was used as nodal heat sources in the stator yoke, stator tooth and rotor yoke. Losses corresponding to the full-load scenario listed in Table III were used, and the other loss components (resistive, mechanical) were kept the same as there was minor change in the full load current due the cutting effect. 


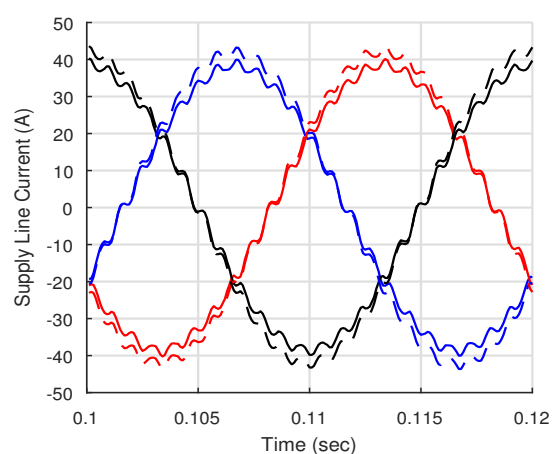

(a)

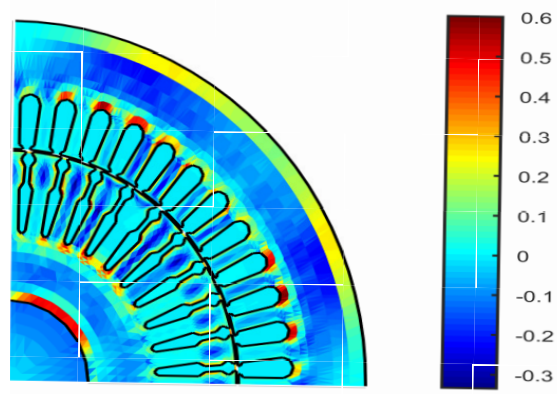

(b)

Fig. 9. (a) Three phase no-load line currents in one supply cycle. Dashed line marker and solid line marker represent supply current with and without cutting effect respectively. (b) Difference in magnetic flux density distribution due to the cutting effect at a time-step.

TABLE IV

TEMPERATURES OF MACHINE PARTS

\begin{tabular}{|c|c|c|c|}
\hline \multirow{2}{*}{ Region } & \multirow{2}{*}{ Node } & \multicolumn{2}{|c|}{ Mean Temperature $\left({ }^{\circ} \mathbf{C}\right)$} \\
\cline { 3 - 4 } & & $\begin{array}{c}\text { Without } \\
\text { cutting } \\
\text { effect }\end{array}$ & $\begin{array}{c}\text { With } \\
\text { cutting } \\
\text { effect }\end{array}$ \\
\hline Stator yoke & 1 & 66.9 & 69.4 \\
\hline Stator teeth & 4 & 73.6 & 76.4 \\
\hline Rotor yoke & 16 & 122.3 & 125.8 \\
\hline Stator end-winding & 6 & 98.8 & 101.1 \\
\hline Stator winding & 7 & 93.9 & 96.5 \\
\hline Rotor bar & 11 & 123.5 & 126.7 \\
\hline
\end{tabular}

The temperatures of different machine part such as core, rotor bars and end-winding were noted. From the results presented in Table IV, it was observed that the core and critical end winding temperatures are increased due to cutting effect.

\section{CONCLUSION AND Discussion}

This paper studies the effect of steel sheet cutting in electrical machines. A simple cutting model of electrical steel sheet is proposed which derived from standard Epstein frame measurements. Some challenges in arriving at the desirable fitting with measurements are also listed. One major challenge is selection of suitable data points for least squares fitting of permeability. The FEM simulation prove

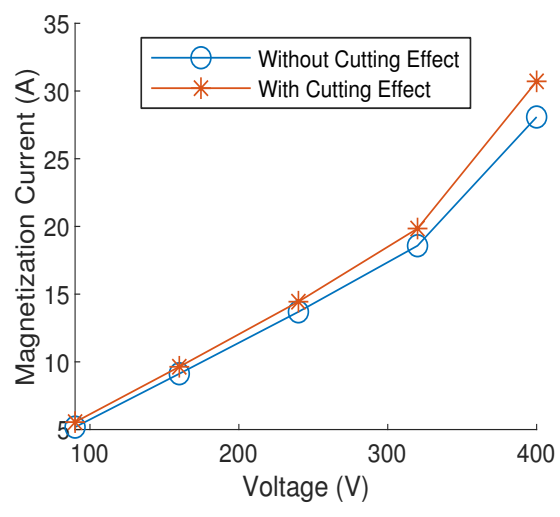

(a)

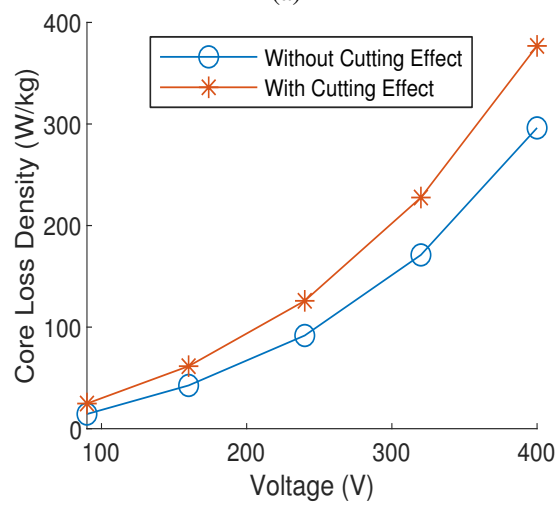

(b)

Fig. 10. (a) No load magnetizing current as function of supply voltage (b) Core loss as function of voltage at no-load.

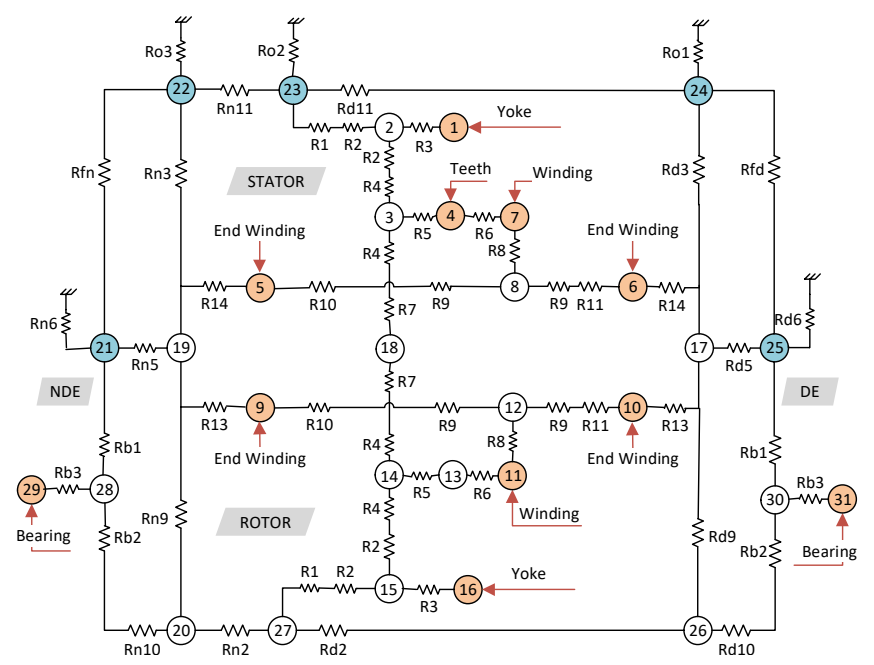

Fig. 11. Thermal network of the $37 \mathrm{~kW}$ cage induction machine.

the applicability of the presented loss model. Further, the cutting model with a time-stepping FEM simulation of a cage induction machine gives insights of corresponding effects on machine performance parameters such as core-losses, supply current and magnetic flux distribution. In future, a stator core of the presented full machine will be manufactured from the same electrical steel extracted from the same steel coil which is presented in this paper. Due to identical steel coil 
for Epstein frame and machine measurements, the measured core-losses should provide high degree of accuracy while quantifying the core-loses and cutting effect.

\section{APPENDIX}

TABLE V

MOTOR DATA

\begin{tabular}{|l|l|}
\hline Shaft Power & $37 \mathrm{~kW}$ \\
\hline Voltage & $400 \mathrm{~V}$ \\
\hline Frequency & $50 \mathrm{~Hz}$ \\
\hline Connection & Star \\
\hline Pole pairs & 2 \\
\hline Stator outer diameter & $310 \mathrm{~mm}$ \\
\hline Stator inner diameter & $200 \mathrm{~mm}$ \\
\hline Air gap & $0.8 \mathrm{~mm}$ \\
\hline Number of stator slots & 48 \\
\hline Number of rotor slots & 40 \\
\hline
\end{tabular}

\section{REFERENCES}

[1] F. Ossart, E. Hug, O. Hubert, C. Buvat, and R. Billardon, "Effect of punching on electrical steels: Experimental and numerical coupled analysis," IEEE Trans. Magn., vol. 36, no. 5, pp. 3137-3140, Sep 2000.

[2] G. Loisos and A. J. Moses, "Effect of mechanical and nd:yag laser cutting on magnetic flux distribution near the cut edge of non-oriented steels," Journal of Materials Processing Technology, vol. 161, no. 1, pp. $151-155,2005$.

[3] V. Manescu-Paltanea, G. Paltanea, and I. V. Nemoianu, "Influence of edge mechanical stress on the $50 \mathrm{hz}$ magnetic properties of thin electrical steel," in 2017 International Conference on Optimization of Electrical and Electronic Equipment (OPTIM) 2017 Intl Aegean Conference on Electrical Machines and Power Electronics (ACEMP), May 2017, pp. 450-455.

[4] T. P. Holopainen, P. Rasilo, and A. Arkkio, "Identification of magnetic properties for cutting edge of electrical steel sheets," IEEE Trans. Ind. Appl., vol. 53, no. 2, pp. 1049-1053, March 2017.

[5] M. Bali, H. D. Gersem, and A. Muetze, "Determination of original nondegraded and fully degraded magnetic properties of material subjected to mechanical cutting," IEEE Trans. Ind. Appl., vol. 52, no. 3, pp. 2297-2305, May 2016.

[6] L. Vandenbossche, S. Jacobs, F. Henrotte, and K. Hameyer, "Impact of cut edges in magnetization curves and iron losses in e-machines for automotive traction," in Proceedings of 25th World Battery, Hybrid and Fuel Cell Electric Vehicle Symposium \& Exhibition, EVS, Schenzhen, China, November 2010. [Online]. Available: http://134.130.107.200/uploads/bibliotest/2010FHCutedge.pdf

[7] H. Sano, K. Narita, E. Zeze, T. Yamada, U. Kazuki, and K. Akatsu, "A practical approach for electromagnetic analysis with the effect of the residual strain due to manufacturing processes," in Proc. 2016 IEEE Energy Conversion Congress and Exposition (ECCE), Sept 2016, pp. $1-7$.

[8] R. Sundaria, A. Lehikoinen, A. Hannukainen, and A. Arkkio, "Higherorder finite element modeling of material degradation due to cutting," in 2017 IEEE International Electric Machines and Drives Conference (IEMDC), May 2017, pp. 1-6.

[9] D. M. Ionel, M. Popescu, S. J. Dellinger, T. J. E. Miller, R. J. Heideman, and M. I. McGilp, "On the variation with flux and frequency of the core loss coefficients in electrical machines," IEEE Trans. Ind. Appl., vol. 42, no. 3, pp. 658-667, May 2006.

[10] L. Salvador, "Inuence of cutting process on magnetic properties of electrical steel," pp. $9+66,2016-10-31$. [Online]. Available: http://urn.fi/URN:NBN:fi:aalto-201611025267

[11] A. Arkkio, "Analysis of induction motors based on the numerical solution of the magnetic field and circuit equations," Ph.D. dissertation, Laboratory of Electromechanics, Helsinki Univ. of Tech., Espoo, 1987.
[12] D. G. Nair, T. Jokinen, and A. Arkkio, "Coupled analytical and 3d numerical thermal analysis of a tefc induction motor," in 2015 18th International Conference on Electrical Machines and Systems (ICEMS), Oct 2015, pp. 103-108.

\section{BIOGRAPHIES}

Ravi Sundaria was born in August 1990. He received the B.Tech. degree from Malaviya National Institute of Technology, Jaipur, India, in 2012 and M.Sc. (Tech.) degree from Aalto University, Espoo, Finland, in 2016 with specialization in electrical machines and drives. He is currently working toward the Ph.D. degree at Aalto University. He worked at Maruti Suzuki India Limited for two years as part of electrical project group. His current research interests include numerical modeling and structural optimization of electrical machines with specific consideration to manufacturing related losses.

Devi Geetha Nair was born in Kerala, India in 1989. She received her B.Tech. degree in electrical and electronics engineering from Amrita University, India and M.Sc. (Tech.) degree in electrical engineering from Aalto University, Finland in 2011 and 2014 respectively. She is currently a doctoral candidate in the Research group of Electromechanics at Aalto University. Her research areas include thermal analysis, inverse thermal modelling, and calorimetric power loss measurement of electrical machines.

Antti Lehikoinen was born in Joensuu, Finland, in 1988. He received the M.Sc. (Tech.) and D.Sc. (Tech.) degrees in electromechanics from the School of Electrical Engineering, Aalto University, Espoo, Finland, in 2013 and 2017, respectively, where he is currently working as postdoctoral researcher. His current research interests include stochastic modeling and prediction of additional losses due to circulating currents in random-wound machines.

Antero Arkkio was born in Vehkalahti, Finland, in 1955. He received the M.Sc. (Tech.) and D.Sc. (Tech.) degrees from the Helsinki University of Technology, Espoo, Finland, in 1980 and 1988, respectively. He is currently a Professor of Electrical Engineering with Aalto University, Espoo. His current research interests include modeling, design, and measurement of electrical machines.

Anouar Belahcen (M13-SM15) received the M.Sc. (Tech.) and Doctor (Tech.) degrees from Helsinki University of Technology, Finland, in 1998, and 2004, respectively. He is now Professor of electrical machines at Tallinn University of Technology, Estonia and Professor of Energy and Power at Aalto University, Finland. His research interest are numerical modeling of electrical machines, magnetic materials, coupled magneto-mechanical problems, magnetic forces, magnetostriction, and fault diagnostics. 